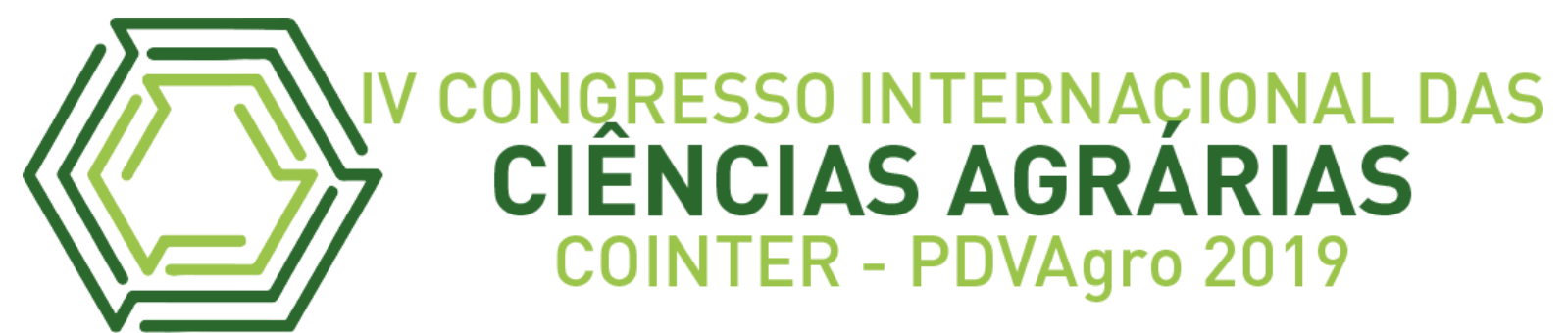

\title{
PERCEPÇÃO DOS MORADORES \\ ENTORNO DOS PROBLEMAS AMBIENTAIS DO RIO ITAPECURU CIDADE DE CODÓ-MA
}

\author{
Apresentação: Comunicação Oral
}

Maria Roselane Alves Oliveira ${ }^{1}$; Alex Jhonne Barbosa Carvalho ${ }^{2}$; Kerlane Alves Fernandes ${ }^{3}$; Irakerley Alves Fernandes ${ }^{4}$; Francisca Inalda Oliveira Santos ${ }^{5}$

\section{DOI: $\underline{\text { https://doi.org/10.31692/2526-7701.IVCOINTERPDVAgro.2019.0034 }}$}

\begin{abstract}
Resumo
O abate de bovinos é uma atividade importante no mercado brasileiro, consequentemente, necessita exercer todas as leis sanitárias e de proteção ao meio ambiente. As águas residuais da atividade contém sangue, gordura, excrementos, substâncias do trato digestivo, além disso, fragmentos de tecidos. A percepção ambiental vem contribuir para prática de ações individuais ou coletivas em relação ao homem e o meio ambiente a partir das expectativas, satisfações ou insatisfações. O presente trabalho teve como objetivo verificar a percepção dos moradores entorno dos problemas ambientais do rio itapecuru na cidade de Codó-MA. A metodologia utilizada foram o levantamento bibliográfico e visita ao local com aplicação de questionários para averiguação da percepção ambiental dos moradores que residem próximo ao rio Itapecuru e matadouro municipal. Os resultados obtidos relatam que os moradores se sentem prejudicados pela degradação do rio no percentual de $65 \%$, em contrapartida $23 \%$ disseram que não e $12 \%$ não souberam responder. Se conhecem o destino dos resíduos do matadouro $71 \%$ discorreram que sim e $23 \%$ dos entrevistados não conhecem e $6 \%$ não souberam responder. Para reduzir o impacto ambiental provocado pelo matadouro próximo as margens do rio Itapecuru seria a mudança de local (43\%), o tratamento adequado dos resíduos (27\%), o reflorestamento da mata ciliar (20) \% e não souberam responder (10\%). Constatouse os seguintes impactos ambientais: lixo, desmatamento, esgoto e urbanização. A maioria dos indagados acreditam que existe a possibilidade de reverter a situação de degradação do rio: mudança de local, tratamento adequado e reflorestamento da mata ciliar.
\end{abstract}

\footnotetext{
${ }^{1}$ Graduanda em Agronomia; Instituto Federal de Educação, Ciência e Tecnologia do Maranhão - IFMA, Campus Codó, roselany.alves@ hotmail.com

${ }^{2}$ Graduado em Agronomia; Instituto Federal de Educação, Ciência e Tecnologia do Maranhão - IFMA, Campus Codó, alex.jbc@ifma.edu.br

${ }^{3}$ Técnica em Química; Universidade Federal do Maranhão - UFMA Campus São Bernardo, kerlanealves@gmail.com

${ }^{4}$ Professora Mestre; Instituto Federal de Educação, Ciência e Tecnologia do Maranhão - IFMA, Campus Codó, irakerley.alves@ifma.edu.br

${ }^{5}$ Professora Mestre, Instituto Federal de Educação, Ciência e Tecnologia do Maranhão - IFMA, Campus Codó, inaldageo@ifma.edu.br
} 
Palavras-Chave: Esgoto. Lixo. Meio Ambiente.

\section{Introdução}

O abate de bovinos é uma atividade importante no mercado brasileiro que deve exercer todas as leis sanitárias e cumprimento das leis de proteção ao meio ambiente. As águas residuais da atividade contém sangue, gordura, excrementos, substâncias do trato digestivo, além disso, fragmentos de tecidos. Se lançadas no meio ambiente sem o prévio tratamento acarretam problemas aos recursos hídricos, a eutrofização, por exemplo. (ROCHA, 2008).

Segundo Feistel (2011) as águas residuais em curso d' água volumosos e perenes são capazes de dissolver a carga recebida sem maiores prejuízos. Porém, em rios de pequeno porte, os efluentes de matadouros tornam as águas receptoras impróprias à vida aquática devido o teor de matéria orgânica.

Os resíduos dos matadouros são agentes de poluição das águas, e, portanto uma ameaça ao meio ambiente e a saúde pública. De tal modo, os resíduos provenientes de matadouros, abatedouros ou frigoríficos carecem de um manejo adequado final antes de serem disseminados nos recursos hídricos.

A percepção ambiental vem contribuir para prática de ações individuais ou coletivas a partir da compreensão da relação entre o homem e meio ambiente nas expectativas, satisfações ou insatisfações, como o indivíduo reconhece o ambiente. (OLIVEIRA, 2005; PACHECO, SILVA, 2007).

Nesse sentido, o presente trabalho teve como objetivo verificar a percepção dos moradores entorno dos problemas ambientais do rio Itapecuru na cidade de Codó-MA.

\section{Fundamentação Teórica}

O matadouro público teve origem nos países europeus e a principal finalidade era o controle dos abates através da vigilância sanitária das carnes. (MUCCIOLO, 1985). No Brasil em 1987 era permitido todo indivíduo ter um local de abate. Mas no mesmo ano foi designado por meio do Decreto Federal 94.554 de 07 de julho 1987 que os matadouros pequenos ou médios deveriam seguir as exigências sanitárias para o funcionamento corretamente (BRASIL, 1987). Entretanto, só no ano de 1988, com a Portaria No 85, de 24 de julho de 1988 foram aprovadas as exigências. Os estabelecimentos que não obedecessem estariam sujeitos às punições. 
Os matadouros são estabelecimentos com infraestrutura destinada ao abate animal, estes locais devem obedecer às normas dos órgãos de fiscalização para que o produto seja de qualidade aceitável ao consumidor (LUGO NETO, 2012). Contudo, os matadouros municipais de pequeno porte, geralmente, não seguem as normas estabelecidas em relação à higiene e/ou fluxograma do abate (LEITE et. al. 2009). As instalações dos matadouros são: currais, rampa, área de atordoamento, sala de matança (sangria, esfola, evisceração, toalete, seções de miúdos), sala de desossa, expedição e setor de utilidades e áreas anexas (SENAI, 2003).

O conceito de resíduo "engloba não somente os sólidos, como também os efluentes líquidos e substâncias presentes nas emissões atmosféricas” (VALLE, 2004 p.95). Os resíduos sólidos são comumente descartados em lixões, aterros, reciclados ou incinerados. Os resíduos líquidos devem ser tratados em ambiente físico, químico ou biológico (PACHECO, 2006).

Os principais resíduos sólidos dos matadouros são: sebo, ossos, esterco, couro, vísceras. Os resíduos líquidos são: sangue, alta carga orgânica, gordura, altos conteúdos de nitrogênio e fósforo (ARAÚJO, COSTA, 2014; DORNELLES, 2009).

\section{Metodologia}

O cenário da pesquisa foi o município de Codó, localizado na região do cerrado maranhense, com uma extensão territorial de 4.982 quilômetros, banhado por três rios Itapecuru, Codozinho e Saco (MOREIRA, 2000).

O matadouro municipal se encontra no bairro São Benedito da cidade de Codó próximo do rio Itapecuru, historicamente a origem do nome Itapecuru é indígena que significa água que caminha entre pedras do tupi "Ita" quer dizer pedra, "pe" que constitui caminho e "curu" significando influência. Este recurso hídrico irriga mais de 50 municípios (UEMA, 2005).

Iniciou-se a pesquisa com levantamento bibliográfico na literatura e aprofundamento do tema estudado a partir de material já publicado: livros, artigos, periódicos, Internet, entre outros. A coleta de dados sobre a percepção ambiental foi obtida por meio de questionários, além de registros fotográficos.

Foi realizada a visita ao local da pesquisa para verificação da percepção dos moradores que residem no entorno do rio Itapecuru na cidade de Codó-MA aplicando questionários semiestruturados sobre questões de faixa etária, renda, escolaridade, moradia, 
problemas ambientais. A análise de dados foi obtida através do programa Microsoft Excel, 2010.

\section{Resultados e Discussão}

Os problemas ambientais são semelhantes nos estados brasileiros, tais como: falta de saneamento básico (esgoto a céu aberto), lixo, desmatamento, queimadas e assoreamento estes os principais na cidade de São Bernardo do Maranhão (SOUSA, BRITO e AMARANTE JUNIOR, 2014). A percepção ambiental da população a propósito pode cooperar para o desenvolvimento de projetos de educação ambiental, além disso, colaborar na tomada de decisões em torno destas questões ambientais.

Este levantamento foi realizado com 34 moradores que residem próximo ao matadouro municipal e o rio Itapecuru na cidade de Codó-MA. Os aspectos sociais dos entrevistados na análise dos dados constataram a predominância de $70 \%$ dos entrevistados do sexo feminino e $30 \%$ do sexo masculino (Gráfico 1). Os valores se aproximam dos obtidos na pesquisa de percepção ambiental de ribeirinhos no estuário do rio anil em São Luís-MA de Martins e Lopes (2009) em que $74 \%$ eram do sexo feminino e $26 \%$ do sexo masculino.

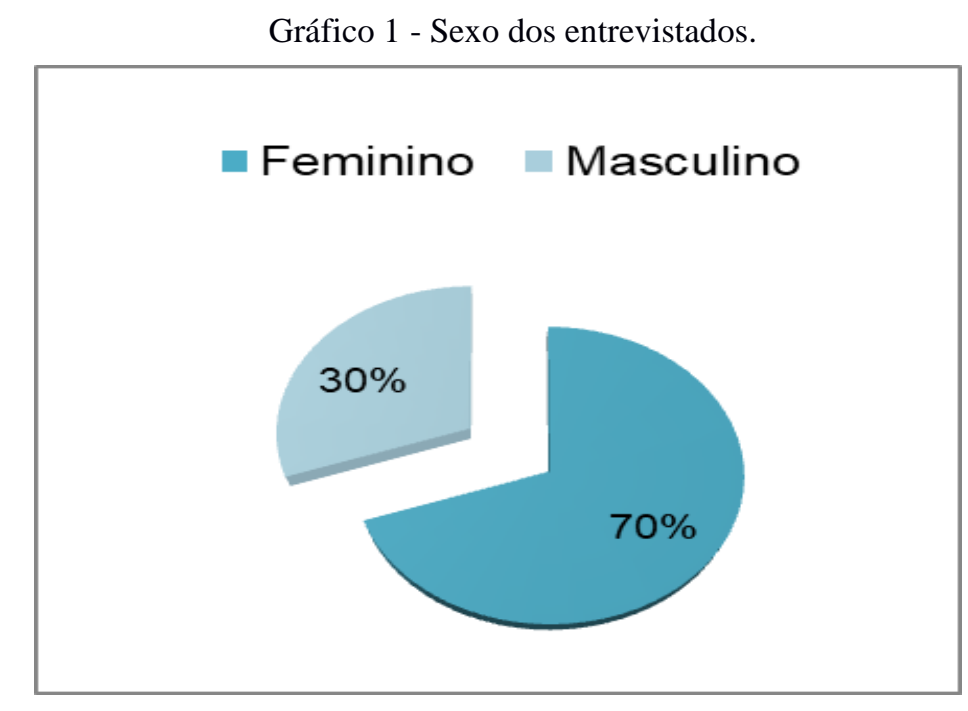

Fonte: Própria (2019)

Quanto a faixa etária dos entrevistados de 18 a 30 e mais de 61 anos de idade apresentou a mesma porcentagem de $21 \%$ dos indagados, entre 31 a 45 anos em torno de $26 \%$, por fim, com 46 a 60 anos foram 32\% dos entrevistados. Ao nível de escolaridade, 32\% 
possuem o ensino fundamental incompleto, $21 \%$ com ensino médio completo, $26 \%$ declararam-se que nunca estudaram mesma percentagem de $6 \%$ educação infantil ou ensino fundamental completo, 9\% com ensino médio incompleto (Gráfico 2). Sousa, Brito e Amarante Junior (2014) encontraram a predominância também do ensino fundamental incompleto em sua pesquisa com $33,6 \%$ dos entrevistados.

Gráfico 2 - Nível de Escolaridade.

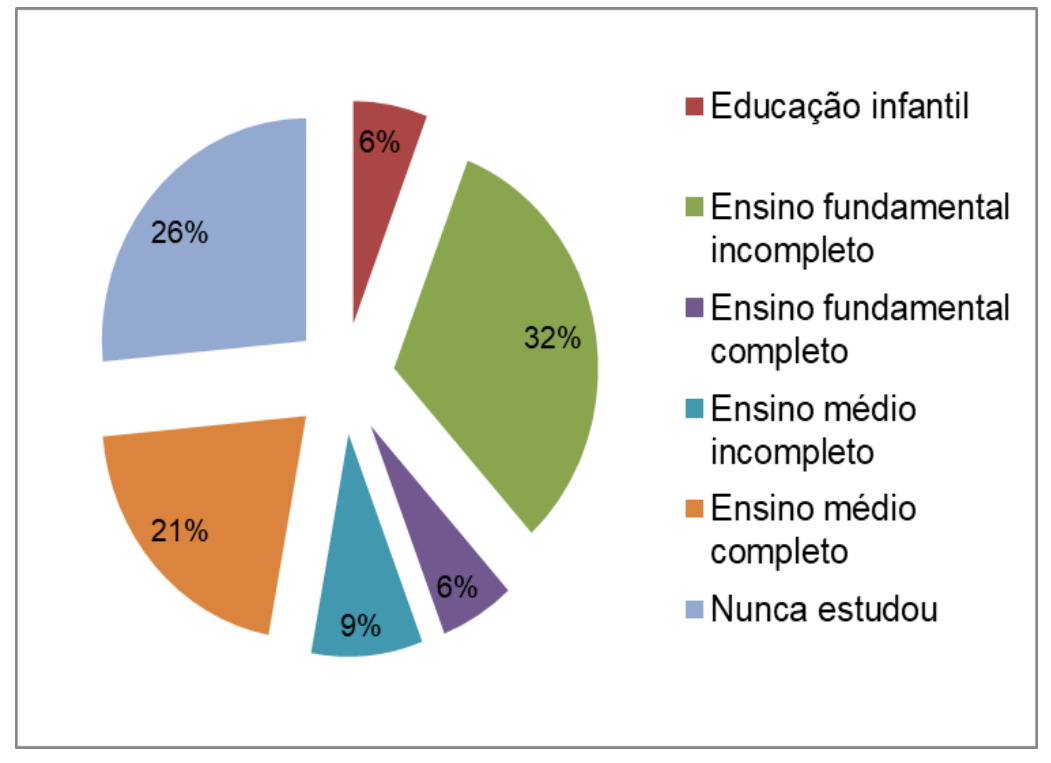

Fonte: Própria (2019)

A situação econômica dos indagados compreende em $26 \%$ menos de 1 salário mínimo e 74\% entre 1 até 2 salários. Quanto tempo reside no lugar $41 \%$ até 30 anos, 23\% até 20 anos, $18 \%$ acima de 30 anos, $12 \%$ até 10 anos e $6 \%$ até 5 anos. Em relação se gostariam de mudar do local da pesquisa verificou-se que $62 \%$ afirmam o apreço pelo lugar que mora, entretanto 38\% disseram se houvesse oportunidade viveria em outro lugar (Gráfico 3).

Gráfico 3 - Gostaria de mudar para outro lugar.

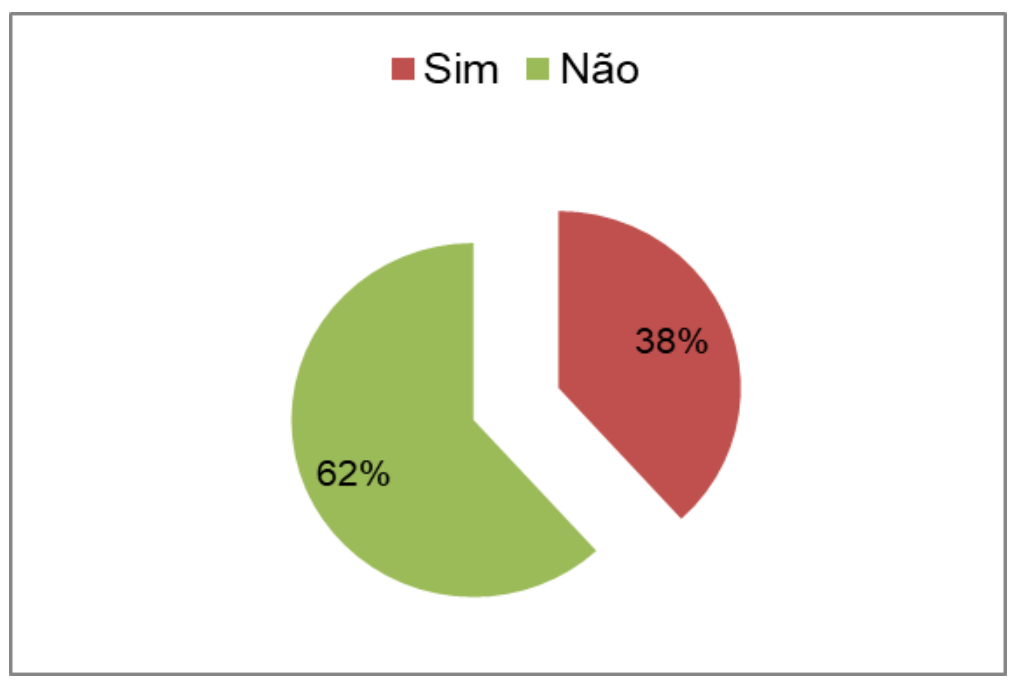


Os problemas ambientais mais visíveis pelos moradores são: 37\% do lixo urbano (Figura $1 \mathrm{~A}$ ); $30 \%$ da retirada da mata ciliar; $21 \%$ do esgoto doméstico e/ou matadouro; $5 \%$ não souberam responder; $4 \%$ a urbanização e 3\% do plantio as margens do rio (vazantes) (Figura 1 B). Sousa, Brito e Amarante Junior (2014) nas entrevistas sobre os impactos ambientais no rio Buriti em São Bernardo-MA expuseram o lixo, desmatamento e esgoto.

Figura 1- (A) Lixo; (B) plantio (lado esquerdo) no rio Itapecuru em Codó-MA.

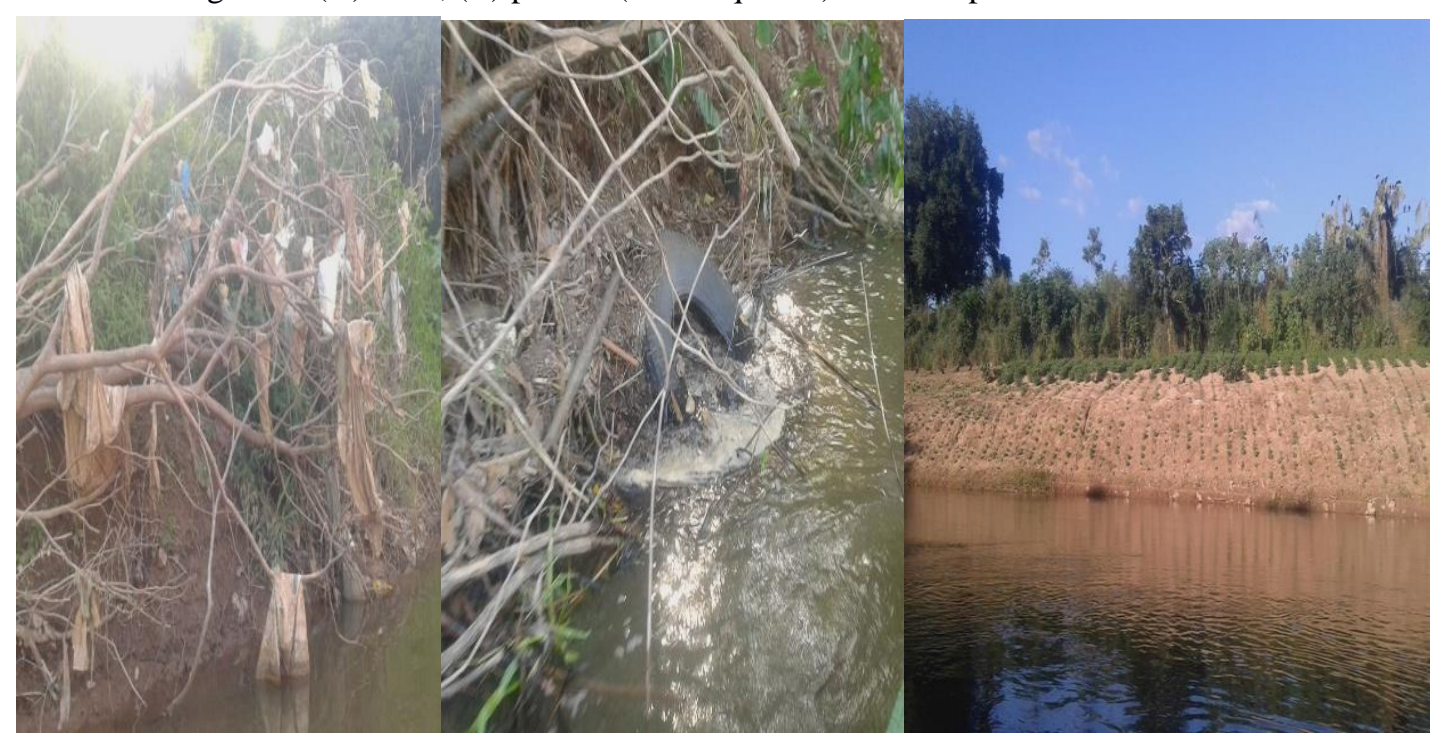

Fonte: Própria (2019)

Na pesquisa o lixo foi apontado dentre os entrevistados como o causador da poluição do rio em que embora exista a coleta municipal os moradores jogam o lixo dentro do rio Itapecuru. $\mathrm{O}$ avanço da urbanização provoca o aumento na quantidade de lixo: industrial, doméstica, hospitalar, comercial, agrícola entre outros. Se houver o manuseio incorreto destes resíduos pode prejudicar a saúde da população.

Os efluentes sem o tratamento nos cursos d'água são agentes de contaminação ao meio ambiente, consequentemente, proliferação de vetores transmissores de doenças aos ribeirinhos (MUCELIN, 2008). Crispim et. al. (2013) descrevem as águas residuais entre os problemas ambientais que mais inutilizam os recursos hídricos.

O desmatamento para finalidade agrícola, conhecida popurlamente como vazante, geralmente o plantio de culturas anuais pode provocar a contaminação dos recursos hídricos pelos agroquímicos aplicados. A exposição da área após colheita causa a erosão do solo, 
consequente, assoreamento, o arraste das partículas de solo para dentro do rio. Na pesquisa de Coelho (2012) relatou no discurso de um agricultor no município de Rosário-MA a justificativa da falta de área ao cultivo agrícola para sua subsistência, por isso, exercia a prática de plantio as margens do rio ainda conhecendo os riscos ambientais.

A mata ciliar desempenha a função de proteção das margens de rios garantindo a filtragem dos sedimentos transportados ou poluentes, se houver. A retirada da mata incide na perda da biodiversidade no local, além disso, alterar-se o índice de luminosidade, composição química e a temperatura da água. (KRUPEK, FELSKI, 2006).

Os esgotos são cargas poluidoras aos recursos hídricos em matéria orgânica que interferem no ecossistema aquático ocasionando a eutrofização que altera o teor de oxigênio, a cadeia alimentar e o fitoplâncton restringindo a qualidade da água (FERREIRA, 2001).

Os moradores se sentem prejudicados pela degradação do rio no percentual de $65 \%$, em contrapartida $23 \%$ disseram que não e $12 \%$ não souberam responder. Para maioria dos entrevistados em 79\% acreditam que haveria possibilidade de reverter esta situação os entrevistados acreditam que por intermédio da sensibilização ambiental dos moradores e políticas ambientais voltadas para recuperação do rio Itapecuru, entretanto 15\% acreditam que não e $6 \%$ não souberam informar (Gráfico 4).

Gráfico 4 - Recuperação do rio Itapecuru em Codó-MA.

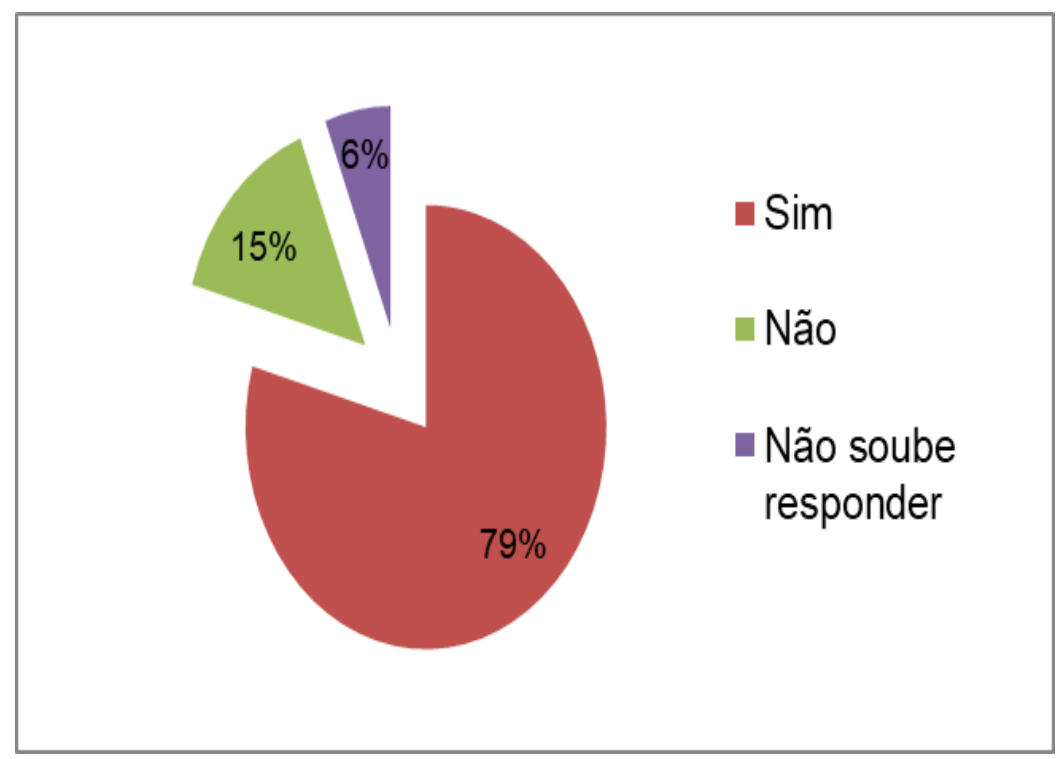

Fonte: Própria (2019) 
Dos recursos que o rio Itapecuru propiciou aos ribeirinhos foram relatados o uso frequente na atividade pesqueira (37\%), a lavagem de roupas (23\%), o próprio banho (20\%), beber água (12\%), não souberam responder $(6 \%)$ e outras finalidades $(2 \%)$.

A localização do matadouro a margem do rio o prejudica para maior parte (73\%) dos entrevistados, porém $24 \%$ falaram que não tem interferência e $3 \%$ não souberam informar. Foram indagados se acreditavam que os resíduos sólidos ou líquidos do matadouro poderiam inutilizar o rio Itapecuru, $82 \%$ afirmam que sim devido à ausência de tratamento dos resíduos, entretanto $15 \%$ não acreditam que possa prejudicar e 3\% não souberam responder (Gráfico 5).

Gráfico 5 - Resíduos prejudiciais ao rio Itapecuru na cidade de Codó-MA.

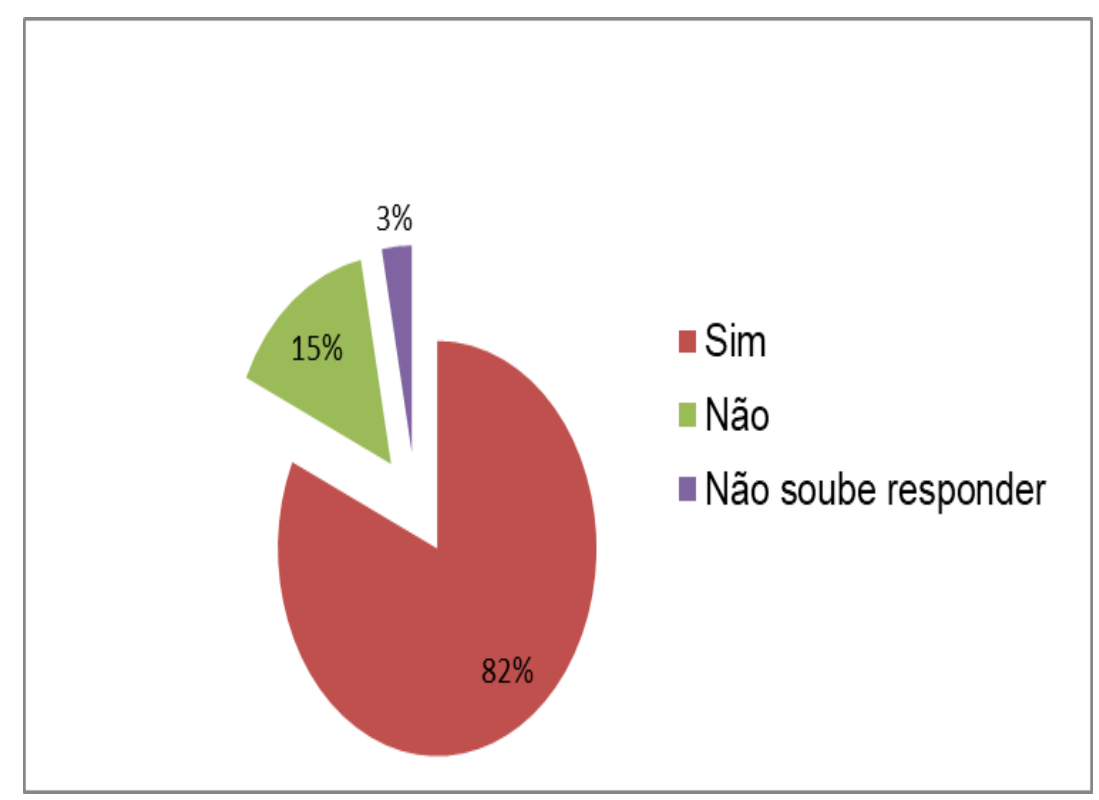

Fonte: Própria (2019)

Foram perguntados se conheciam o destino dos resíduos (Figura 2) do matadouro 71\% discorreram que sim. São lançados no rio, lixão e aterro sanitário, todavia no município ainda não tem este tipo de tratamento do lixo, $23 \%$ dos entrevistados não conhecem o destino e $6 \%$ não souberam responder (Gráfico 6).

O problema do rejeite destes resíduos em lixões ou em outro local inadequado segundo Araújo e Silva (2014) é a proliferação de trasmissores de doenças: moscas, ratos e urubus, gerando riscos a população que tenham contato com o local ou moram próximo. 
Figura 2 - Resíduos líquidos e sólidos lançados no rio Itapecuru.

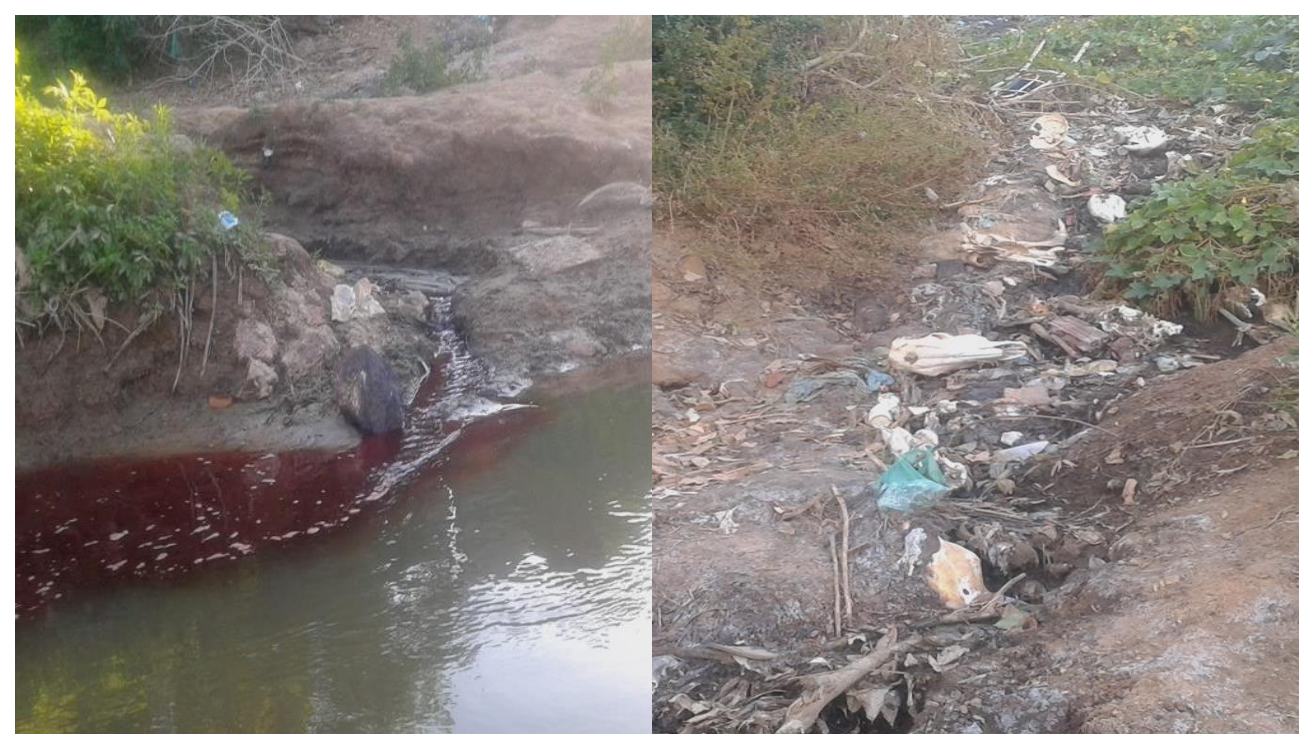

Fonte: Própria (2019)

Gráfico 6 - Destino dos resíduos na cidade de Codó-MA.

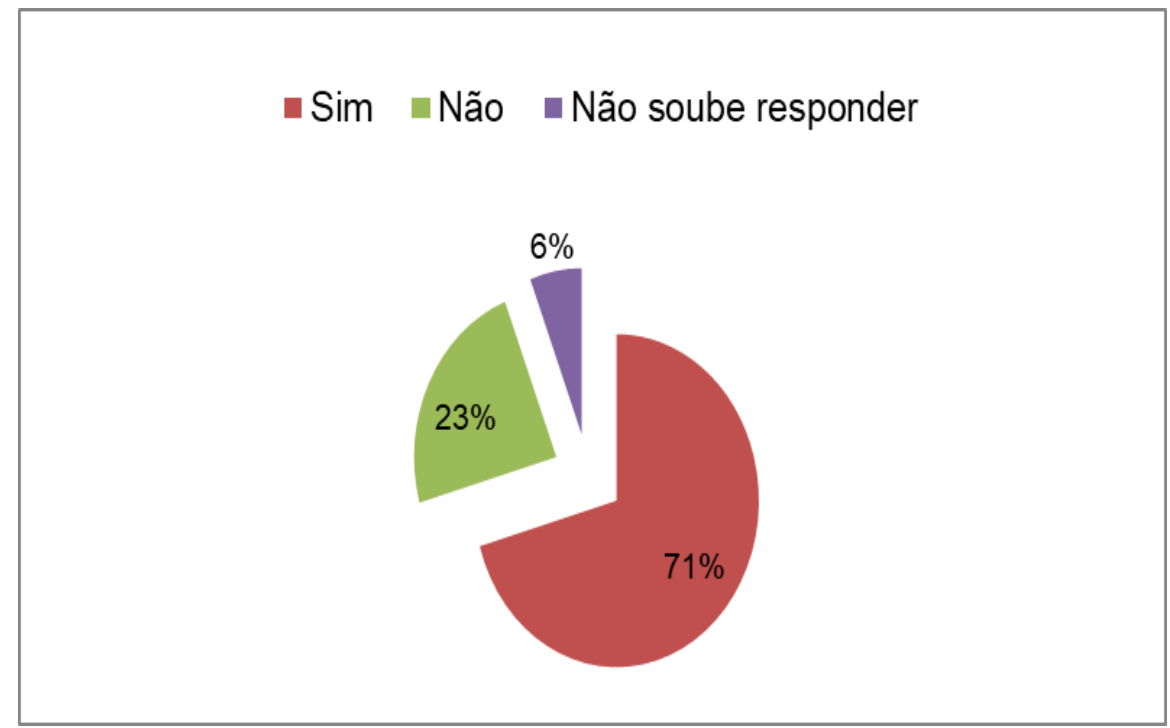

Fonte: Própria (2019)

O matadouro municipal foi instalado no bairro São Benedito de Codó-MA no ano de 1980 hoje o funcionamento é regido pela lei de $\mathrm{n}^{\mathrm{o}} 1.518$ de 21 de junho de 2010 . O monitoramento de inspeção da sanidade dos bovinos e infraestrutura do local é realizada pelo Serviço de Inspeção Municipal (SIM) vinculado à secretária de agricultura do munícipio. Foi 
perguntado se o local causava mau cheiro causando desconforto $59 \%$ responderam que sim e $41 \%$ não se sentem incômodos (Gráfico 7). Os resíduos orgânicos são altamente putrescíveis e podem incomodar as pessoas que vivem próximas (ARAÚJO E COSTA, 2014).

Gráfico 7 - Mau cheiro do matadouro.

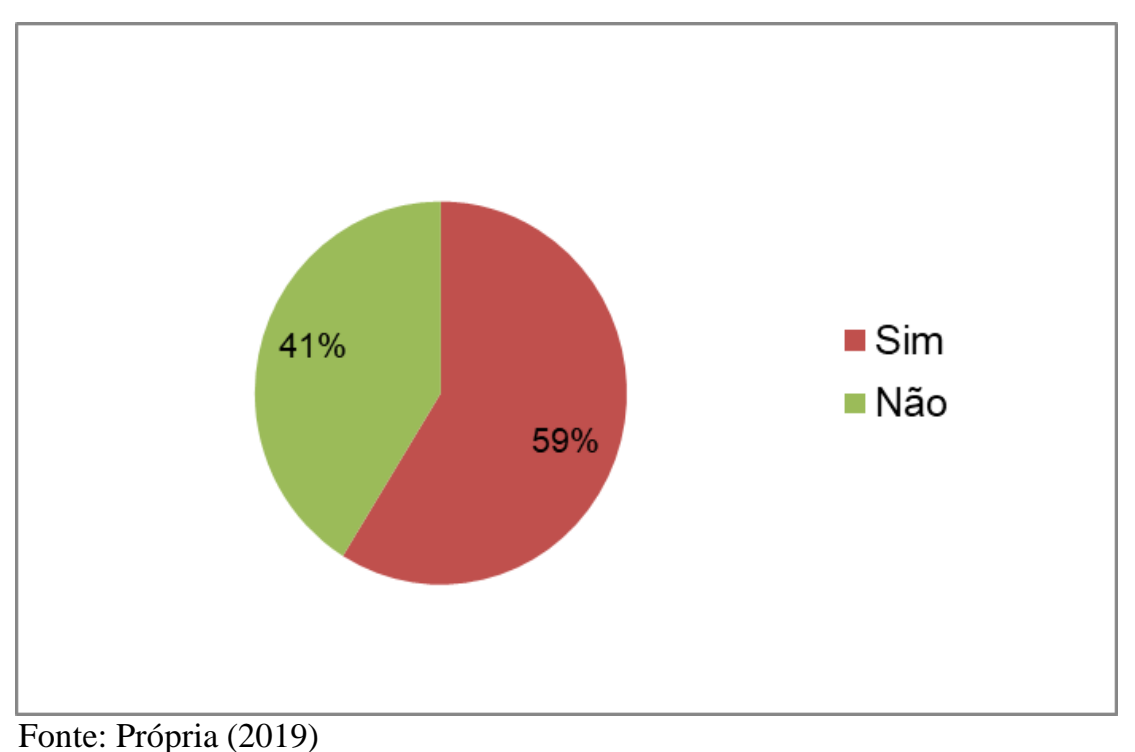

Na percepção dos moradores para reduzir o impacto ambiental do matadouro próximo as margens do rio Itapecuru seria mudança de local (43\%), o tratamento adequado dos resíduos (27\%), reflorestamento da mata ciliar (20) \% e não souberam responder (10\%) (Gráfico 8). Foram investigados se o poder público tem realizado ações para minimizar o problema, $44 \%$ responderam que sim, no entanto $38 \%$ disseram não observar nenhuma iniciativa e $18 \%$ não souberam responder.

Gráfico 8 - Reduzir o impacto ambiental ao rio Itapecuru.

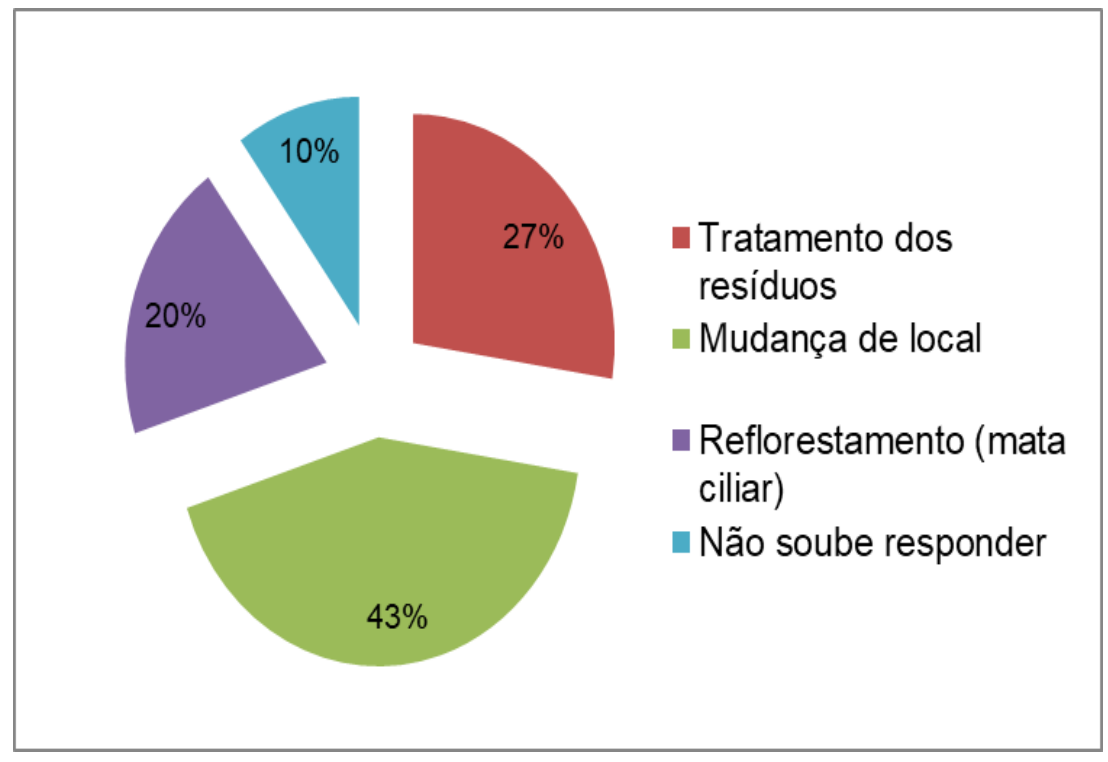


Ao questionamento do local de moradia sobre a presença de insetos e roedores de doenças com procedência devido atividade do matadouro $53 \%$ sim, frequentemente, $38 \%$ às vezes, $3 \%$ disseram que não observam, $3 \%$ outros, por exemplo, urubus e $3 \%$ não souberam responder a esta pergunta (Gráfico 9). Por fim, se adquiriu alguma(s) doença(s) que pode haver com o local que você vive $85 \%$ disseram que não, todavia $15 \%$ relatam que sim.

Pestana (2015) em sua pesquisa de saneamento entorno da lagoa do Vigário em Campos dos Goytacazes - RJ revela que 47\% dos moradores observam frequentemente animais vetores de doenças, mas não especificaram quais seriam esses vetores na comunidade. A ineficiência do saneamento básico (coleta de esgotos e/ou resíduos) incidem no aparecimento de insetos, roedores ou outros animais transmissores de doenças. (SANTANA; LUVIZOTTO; CUBA, 2012).

Gráfico 9 - Presença de insetos e roedores

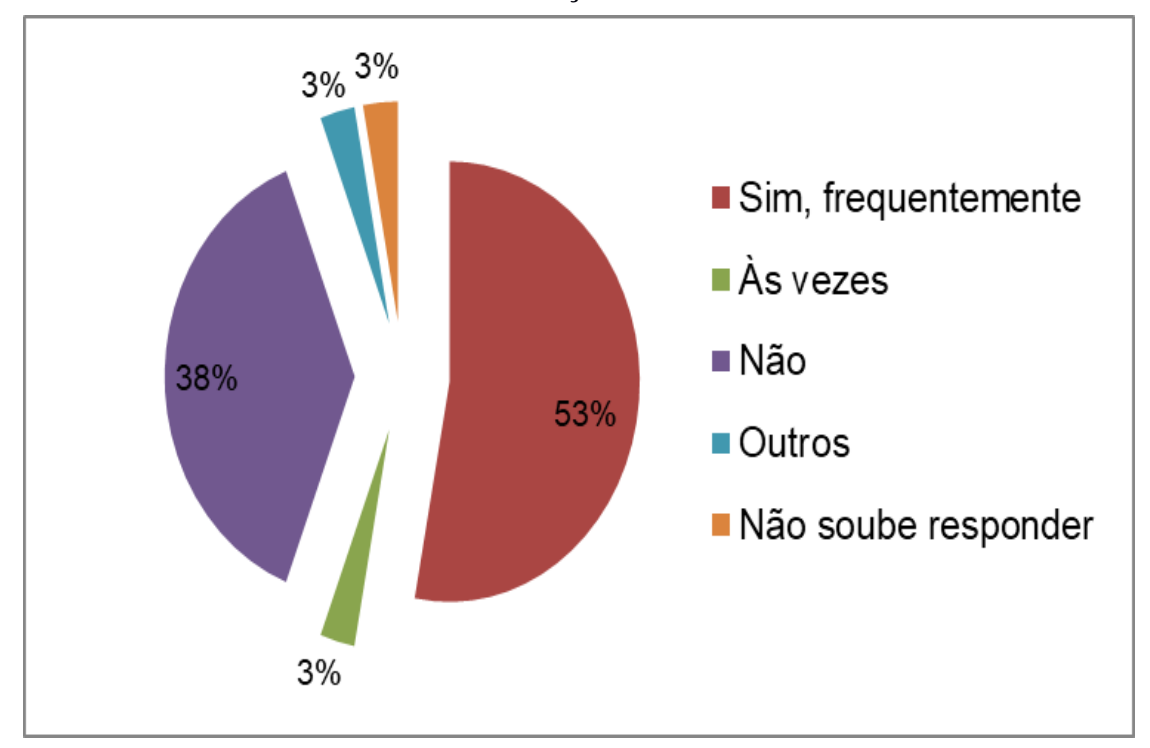

Fonte: Própria (2019)

\section{Conclusões}

Constatou-se que o matadouro municipal na percepção dos entrevistados prejudicou o rio Itapecuru por causa do manuseio inadequado dos resíduos líquidos e sólidos provenientes da atividade. Os principais impactos ambientais são: lixo, desmatamento, esgoto e urbanização. A maioria dos indagados acreditam que existe a possibilidade de reverter a 
situação de degradação: mudança de local, tratamento adequado e reflorestamento da mata ciliar.

\section{Referências}

ARAUJO, P. P. P.; COSTA, L. P. Impactos Ambientais nas Atividades de Abate de Bovinos: Um Estudo no Matadouro Público Municipal de Caicó-RN. HOLOS. ISSN 1807-1600. 2014. Disponível em: < fcst.edu.br/site/wpcontent/uploads/2015/04/artigo_matadouro_caico.pdf>. Acesso em 06 de ago. de 2019.

BRASIL. Ministério da Agricultura, Pecuária e Abastecimento. Decreto Federal 94.554, de 07 de julho de 1987. Dispõe sobre estímulos à construção e reaparelhamento de pequenos e médios matadouros e sua fiscalização. 1987. Disponível em:

<http://www2.camara.leg.br/legin/fed/decret/1980-1987/decreto-94554-7-julho-1987-444453publicacaooriginal-1-pe.html>. Acesso em 10 de ago. 2019.

COELHO, A. A. Percepção Ambiental dos moradores ribeirinhos do médio Itapecuru em Rosário-MA como subsídio a uma proposta de Educação Ambiental. Revbea, Rio Grande, V. 7, No 2: 29-36, 2012. Disponível em:

$<$ http://repositorio.furg.br/bitstream/handle/1/4129/Percep\%C3\%A7\%C3\%A3o\%20Ambienta 1\%20dos\%20Moradores\%20Ribeirinhos\%20do\%20Medio\%20Itapecuru\%20em\%20Rosario. pdf? sequence $=1>$. Acesso em 06 de ago. de 2019.

CRISPIM, D. L., LEITE, R. P., CHAVES, A. D. C. G., MARACAJÁ, P. B., BARBOSA, R. C. A., CAJÁ, D. F. Diagnóstico ambiental do rio Piancó próximo ao perímetro urbano da cidade de Pombal-PB. Revista Brasileira de Gestão Ambiental, n.7, v. 3, p. 01-06, 2013.

DORNELLES, F. Análise da gestão dos tratamentos de efluentes gerados nos abatedouros de bovino de São Luís Gonzaga. Santa Maria (RS), 2009. 103 fl. Dissertação (Mestrado em Engenharia de Produção) - Universidade de Santa Maria (UFSM). Disponível em: 〈http://livros01.livrosgratis.com.br/cp090624.pdf〉. Acesso em 15 de ago. de 2019.

FEISTEL, J. C. Tratamento e destinação de resíduos e efluentes de matadouros e abatedouros. 2011. (Sanidade Animal, Higiene e Tecnologia de Alimentos) - Universidade Federal de Goiás Escola de Veterinária e Zootecnia, Goiânia. Disponível em:

<https://portais.ufg.br/up/67/o/semi2011_Janaina_Costa_2c.pdf >. Acesso em 10 ago. 2019.

FERREIRA, S. M. de. Impacto da eutrofização em Cyathuracarinata (Isopoda), no estuário do Modengo, 2001. 144 f. Dissertação ( Mestrado em Ecologia)- Universidade de Coimbra, 2001. Disponível em: <https://eg.sib.uc.pt/bitstream/10316/13445/1/Impacto\%20da\%20eutrofiza\%C3\%A7\%C3\%A 3o\%20em\%20Cyathura\%20carinata.pdf>. Acesso em 08 ago. 2019.

KRUPEK, R. A.; FELSKI, G. Avaliação da cobertura ripária de rios e riachos da Bacia Hidrográfica do Rio das Pedras, Região Centro-Sul do Estado do Paraná. Revista Ciências Exatas e Naturais, v.8, p.179-188, 2006. 
LEITE, A. I. et al. Condições físicas e higiênico sanitárias dos matadouros municipais da região oeste do Rio Grande do Norte, Brasil. Rev. Arq. Inst. Biol., São Paulo, v.76, n. 3,2009. Disponível em: <www.biologico.sp.gov.br/docs/arq/v76_3/leite.pdf>. Acesso em 15 de ago. de 2019.

LUGO NETO, D. F. Perfil social e risco ocupacional dos trabalhadores do matadouro de Sapé/PB. 2012. 55 f. Monografia (Especialização de Gestão em Saúde). Universidade Estadual da Paraíba, Polo de Educação à Distância, João Pessoa, 2012. Disponível em:

<http://dspace.bc.uepb.edu.br:8080/jspui/bitstream/123456789/2461/1/PDF\%20\%20Domingos\%20Fernandes\%20Lugo\%20Neto.pdf>. Acesso em: 15 ago. 2019.

MARTINS, A. L. P.; LOPES, M. J. S. Caracterização da população ribeirinha do estuário do Rio Anil (São Luís - MA), com base em aspectos sociais, econômicos e ambientais. Boletim do Laboratório de Hidrobiologia, São Luís, v.22, n.1, p.9-16, 2009.

MOREIRA, Colares Enciclopédia do Maranhão. História de Codó, São Luís, v.49, n. 2, 2000 .

MUCCIOLO, P. Carnes: Estabelecimentos de Matança e de industrialização. São Paulo: Ícone, 1985. 100p.

MUCELIN, Carlos Alberto and BELLINI, Marta. Lixo e impactos ambientais perceptíveis no ecossistema urbano. Soc. nat. [online]. 2008, vol.20, n.1, pp. 111-124. ISSN 1982-4513

OLIVEIRA, S.K.S. Percepção da Educação Ambiental e Meio Ambiente no Ensino Fundamental: Olhares em Porto do Mangue/RN. Dissertação de Mestrado (Mestrado em Desenvolvimento e Meio Ambiente). UERN. Mossoró-RN. 119p. 2005.

PACHECO, J. W.; YAMANAKA, H. T. Guia Técnico Ambiental de Abates (Bovino e Suíno). São Paulo: Cetesb, 2006.

PACHECO, E.; SILVA, H. P. Compromissos Epistemológicos do Conceito de Percepção Ambiental. Rio de Janeiro. Departamento de Antropologia, Museu Nacional e Programa EICOS/UFRJ, 2007.

PESTANA, M. dos S. V. Saneamento: Um indicador de qualidade de Vida na comunidade do Entorno da Lagoa do Vigário. Trabalho de conclusão de curso (monografia) - IFF, Campos dos Goytacazes, RJ, 2015. Disponível em: < http://bd.centro.iff.edu.br/bitstream/123456789/529/1/Monografia\%20corrigida\%20pela\%20b anca\%20vers\%C3\%A3o\%20final.pdf>. Acesso em 15 de ago de 2019.

ROCHA MARIA, R. Avaliação da eficiência no tratamento de efluentes líquidos em frigoríficos. UDC. Foz do Iguaçu, 2008.

SOUSA, E.O.F.; BRITO, N.; AMARANTE JUNIOR, O. P. Percepção ambiental da população urbana próxima ao rio Buriti no município de São Bernardo, MA. Pesquisa em Educação Ambiental. (Online), v. 9, p. 37-50, 2014. Disponível em:<https://www.revistas.usp.br/pea/article/view/128692>. Acesso em 10 de ago. de 2019. 
SANTANA, A. T.; LUVIZOTTO, C. K.; CUBA, R. M. F. Saneamento básico e sua relação com a qualidade de vida nos assentamentos do município de Teodoro Sampaio - SP. VIII Fórum Ambiental da Alta Paulista. v. 8, n. 12, [s.l.]: ANAP. [s.d.]. p. 48-62, 2012. Disponível em:<https://www.amigosdanatureza.org.br/publicacoes/index.php/forum_ambiental/article/vi ew/354>. Acesso em 15 de ago. 2019.

SERVIÇO NACIONAL DE APRENDIZAGEM INDUSTRIAL DO RIO GRANDE DO SUL. Princípios básicos de produção mais limpa em matadouros frigoríficos. Porto Alegre: UNIDO, UNEP, Centro Nacional de Tecnologias Limpas SENAI, 2003. Disponível em: <http://institutossenai.org.br/public/files/principios-basicos-de-producao-mais-limpa-emmatadouros-frigorificos.pdf $>$. Acesso em 05 de ago. 2019.

UNIVERSIDADE FEDERAL DO MARANHÃO. Laboratório de recursos hídricos: bacias hidrográficas. São Luis: EDUEMA, 2005.

VALVERDE, S.R. Elementos de Gestão ambiental empresarial, Viçosa, $1^{\circ}$ reimpressão, 2008.

VALLE, C. E. do. Qualidade ambiental: ISO 14000. 5.ed. São Paulo: SENAC, 2004 